\title{
Erratum to: Analytical method for assessing potential dermal exposure to pesticides of a non-agricultural occupationally exposed population
}

\author{
Olivier Delhomme • Caroline Raeppel • \\ Delphine Teigné • Olivier Briand • Maurice Millet
}

Published online: 10 January 2012

(C) Springer-Verlag 2011

\section{Erratum to: Anal Bioanal Chem \\ DOI 10.1007/s00216-010-4434-9}

Following publication, the authors would like to add the following comments and amendments.

\section{General comment:}

This paper is a specific part of a research project "Development of an integrated method for estimation of pesticide exposure for a non-agricultural occupationally exposed population" and is devoted to the development of an analytical method for assessing dermal exposure.

\section{Authors of the article:}

An author was omitted: Delphine Teigné from Cnam IHIE-Ouest.

Cnam IHIE-Ouest coordinated the project "Development of an integrated method for estimation of pesticide exposure for a

The online version of the original article can be found at http://dx.doi. org/10.1007/s00216-010-4434-9.

O. Delhomme $\cdot$ C. Raeppel $\cdot$ M. Millet $(\bowtie)$

Equipe de Physico-Chimie de l'Atmosphère,

LMSPC (UMR 7515 CNRS, Université de Strasbourg),

1 rue Blessig,

67084 Strasbourg, Cedex, France

e-mail: millet@illite.u-strasbg.fr

D. Teigné

Cnam IHIE Sset Ouest,

18 rue de Nazareth,

49100 Angers, France

e-mail: d.teigne@cnam-paysdelaloire.fr

O. Briand

ANSES,

27-31 avenue du Général Leclerc,

94701 Maisons-Alfort, Cedex, France non-agricultural occupationally exposed population", from which arises the topic of the paper. Measurement of dermal exposure was performed entirely by Delphine Teigné. Table 2 and Fig. 3, in which amounts of dermal exposure are reported, were produced by Delphine Teigné. These results were used to illustrate and validate the method developed by the "Equipe de Physico-Chimie de l'Atmosphère de l'Université de Strasbourg/CNRS". These results were also presented as the paper: Development of an integrated method for estimation of pesticide exposure for a non-agricultural occupationally exposed population G. Auburtin, D. Teigné, O. Briand, O. Delhomme, S. Dulaurent, M. Millet, Ch. Moesch, L. Tuduri, L. Racault in posters and oral communications at, and in the proceedings of, the 7th International Conference on Air Quality, Istanbul, Turkey, 24-27 March 2009. ISBN: 978-1-905313-64-8 (available from the University of Hertfordshire, UK):

Unfortunately, these proceedings were not mentioned in the list of references of the paper.

\section{Introduction}

\section{Financial support:}

This paper is a specific part of a research project funded by "ANSES" (formerly AFSSET) and by the "Fonds National de Prévention (FNP) de la Caisse Nationale de Retraite des Agents des Collectivités Locales (CNRACL)".

\section{Partners involved on the project:}

Conservatoire National des Arts et Métiers (Cnam), Institut d'hygiène industrielle et de l'environnement, Ouest (IHIE, Ouest), Angers (France) 
Leaders: Guy Auburtin (coordinator), Delphine Teigné (2007-2011)

Service de Pharmacologie et de Toxicologie du CHU de Limoges (France)

Leaders: Gérard Lachâtre, Christian Moesch, Sylvain Dulaurent (2007-2011)

Université de Strasbourg, LMSPC (UMR 7515), Equipe de physicochimie de l'atmosphère

Leaders: Maurice Millet (2007-2011), Olivier Delhomme (2007-2008), Caroline Raeppel (2008-2011)

Equipe Périgourdine de Chimie Appliquée/Institut des Sciences Moléculaires (EPCA/ISM) Université Bordeaux 1, UMR CNRS 5255, Périgueux (France)

Leader: Ludovic Tuduri (2007-2011)

Service de Médecine du travail, Direction des ressources humaines, Hôtel de Ville, Angers (France)

Leader: Dr Marie Pierre Levy (2007-2011)

\section{Specific objective:}

The topic of the article is a specific part of one of the objectives of the research project "Development of an integrated method for estimation of pesticide exposure for a non-agricultural occupationally exposed population". This objective is the development of methods for measurement of individual exposure (dermal exposure, air exposure, and impregnation).

\section{Groups of studies:}

Workers of two communities participated to the project. These communities are Angers city and its agglomeration Angers Loire Metropole.

Because no "non-exposed group" was analysed, the text in the paper ".. and an unexposed reference group from the same area" must be removed.

\section{Experimental Field Observations:}

"Nine operators working for Angers city"

\section{Sampling:}

In the section on the relative precision of the method for measurement of exposure of hands the text must be changed to:

-“...by wiping both hands with two patches of sterile cotton gauze wetted with ..."

-"Samples were frozen within 2 hours of sampling."

\section{Results and discussion}

Table 2: the "b)" cannot be attributed to hands and gloves contamination but to real all-body exposure only.

Conclusions from Table 2 and Figure 3 must be interpreted as follows:

"These preliminary results show the analytical possibility of monitoring exposure to pesticides of non-agricultural workers by determination of skin concentrations (Fig. 3). Additional measurements are needed for sound explanations, but these first results show that workers who do not apply the pesticides directly are also exposed, perhaps less than appliers, and that backpack sprayers could be responsible for greater exposure than motorized sprayers. The effect of protective clothing must be taken into account (Table 2).

In a second phase of the study, more extensive sampling trials are planned to study the effect of air and skin conditions and possible relationships between these and exposure determined by analysis."

\section{Acknowledgements}

Workers of Angers city and Angers Loire Metropole are gratefully acknowledged for participating in the sampling campaigns.

ANSES and FNP-CNRACL are also gratefully acknowledged for funding this study. 